\title{
Knowledge and Perceptions of Undergraduate and Postgraduate Nursing Students About the Use of 3D Digital Printing in Healthcare
}

\author{
Sotirios ANAGNOSTOPOULOS ${ }^{\mathrm{a}, 1}$, Parisis GALLOS ${ }^{\mathrm{a}}$, Emmanouil ZOULIAS $^{\mathrm{a}}$, \\ Nikolaos FOTOS ${ }^{\mathrm{a}}$ and John MANTAS ${ }^{\mathrm{a}}$ \\ ${ }^{a}$ Faculty of Nursing, School of Health Sciences, National and Kapodistrian University \\ of Athens, Greece
}

\begin{abstract}
D printing is applicable in various fields. The purpose of this study was to explore the knowledge and perceptions of undergraduate and postgraduate nursing students in relation to the use of $3 \mathrm{D}$ printing. A questionnaire was developed including questions about demographics, the students' knowledge about, and the student's attitude towards the 3D printing technology. Descriptive statistics and correlations were examined. The average knowledge score was 2.6 out of 6 and the perception score was 7.7 out of 10 . Only gender was found to be related with $3 \mathrm{D}$ printing knowledge. Gender, age, and educational level were related with students' attitude towards $3 \mathrm{D}$ printing.
\end{abstract}

Keywords. 3D printer, education, applications of 3D printing, Knowledge, Attitude

\section{Introduction}

3D printing is applicable in various fields. The manufacture of additives is in a unique position to support the lack of critical medical devices. It has been observed that the applications of 3D technology in the field of Health Sciences are an important tool for routine interventions and for better training of health personnel [1,2]. The purpose of this study was to explore the knowledge and perceptions of undergraduate and postgraduate nursing students in relation to the use of $3 \mathrm{D}$ printing.

\section{Methods}

In order to gather the required information, a 16-item questionnaire was created. The first section recorded the demographic characteristics of the students and the second section contained six questions, where the students' knowledge was explored. In the third section there were ten questions about the student's attitude towards the 3D printing technology. Descriptive statistics and correlations between the study values were obtained.

${ }^{1}$ Corresponding Author, Anagnostopoulos Sotirios, MSc, Health Informatics Laboratory, School of Health Sciences, National and Kapodistrian University of Athens, Greece; E-mail: sotanagn@yahoo.com. 


\section{Results and Discussion}

The study population included 364 (89.02\% response rate) participants with a mean age of 24.7 years, and $80.8 \%$ were women. $62.4 \%$ were undergraduate students. $89.9 \%$ used the internet moderately to very much for scientific purposes. Regarding the participant's knowledge of 3D printing, it seems that they had heard about the use of 3D printers $(78.8 \%)$, but few had access to them $(0.5 \%)$ or had attended any courses for $3 \mathrm{D}$ printing $(3,6 \%)$. The average knowledge score was 2.6 out of 6 , both for the uses and applications. Regarding the participants' perceptions of 3D printing, there is an attitude score that takes values from 0 - 10 . Higher scores mean more knowledge and a more positive attitude. The average perception score was 7.7 and the standard deviation was 1.5 , and this can be assumed as a positive result. Most said that 3D printers have advantages (97\%) and would help improve education (94\%) and improve patient's quality of life (86.5\%). Only gender was found to be related with 3D printing knowledge. Specifically, males were more knowledgeable about the applications of 3D printers than females $(p<0.001)$. On the other hand, regarding the students' attitude towards 3D printing, gender, age, and educational level were found to be significantly important. According the international literature, other researchers have shown that medical students or physicians have developed a positive perception of the new education methodology $[3,4]$ and show that there is great interest in the latest advances in 3D printing technology in clinical practice $[5,6]$. The increasing use of the internet for scientific purposes has been associated with more knowledge about the applications and uses of 3D printers. No study has been found in Greece or internationally that evaluates the impact of the education of nurses or nursing students in relation to knowledge and perceptions about the use of 3D printing.

\section{Conclusions}

Both Undergraduate as well as, Postgraduate Nursing students seem to have positive attitude towards 3D printing technologies and they believe that these technologies can be applied in Healthcare domain. Future work may include further knowledge development about 3D printing usage and applications.

\section{References}

[1] Ahangar P, Cooke ME, Weber MH, Rosenzweig DH. Current Biomedical Applications of 3D Printing and Additive Manufacturing. Appl Sci 2019;9(8): 1-23.

[2] Aimar A, Palermo A, Innocenti B. The Role of 3D Printing in Medical Applications: A State of the Art. Hindawi, J Healthc Eng 2019;2019:1-10.

[3] Wilk R, Likus W, Hudecki A, Syguła M, Różycka-Nechoritis A, Nechoritis K. What would you like to print? Students' opinions on the use of 3D printing technology in medicine. PLoS One 2020;15(4):1-16.

[4] Alyami H, Alawami M, Lyndon M, Alyami M, Coomarasamy C, Henning M, Hill A, Sundram F. Impact of Using a 3D Visual Metaphor Serious Game to Teach History-Taking Content to Medical Students: Longitudinal Mixed Methods Pilot Study. JMIR Serious Games. 2019 Sep 26;7(3):e13748.

[5] Parikh M, Kulkarni N, Parikh M. Knowledge, attitude, and practice on 3D printing among orthodontist in India - An online questionnaire study. IJARnD 2019;4(3):26-30.

[6] Salvador Verges À, Fernández-Luque L, López Seguí F, Yildirim M, Salvador-Mata B, García Cuyàs F. Orthopedic Surgeons' Perspectives on the Decision-Making Process for the Use of Bioprinter Cartilage Grafts: Web-Based Survey. Interact J Med Res. 2019 May 15;8(2):e14028. 